\title{
Assessment of vulnerability of the underground aquatic systems by radioactive contamination using the ultrasensitive radiochemical methods
}

\author{
MICHAL FEJGL*
}

Bartoškova 28, Prague 4, Czech Rep. (michal.fejgl@suro.cz)

Aim of this contribution is to present a study comprising development of ultrasensitive radiochemical analytical procedures for determination of ${ }^{137} \mathrm{Cs},{ }^{90} \mathrm{Sr}$ and ${ }^{3} \mathrm{H}$ activity concentration in water samples and their utilization for assessment of the vulnerability of underground drinking water sources by radioactive contamination. The study covers a territory of the Czech Republic.

Underground water sources are expected to provide the main capacity of the emergency water sources. There are 152 hydrogeological districts defined in the Czech Republic.

In case of a nuclear accident the underground water source would be protected against radioactive contamination for a time interval called a period of protection (i.e. the delay between surface and underground contamination). For most of the hydrogeological districts in the Czech Republic the period of protection is not known.

Thanks to nuclear weapon tests in 1950s and 1960s and to the Chernobyl NPP accident rain water was unintentionally labelled. Time course of activity concentrations in rainwater for the most important radionuclides in the last 70 years is well recorded.

Radiochemical analytical methods, including State of the Art method for Tritium determination combined with progressive methods for ${ }^{90} \mathrm{Sr}$ and ${ }^{137} \mathrm{Cs}$ determination, are going to be employed to perform extra sensitive analyses. A mathematical modelling associating determined activity concentrations of mentioned radionuclides and activity concentration records in rain waters with the main hydro-geological features enables to determine a time gap between a moment when contaminated rain drops on the Earth surface and penetration to each of the hydro-geological body. This study is supported by the institutional funding of the Czech Ministry of the Interior of the Czech Republic (project VI20192022142). 